\title{
Reasons for Choosing the Traditional Method (Withdrawal) as Contraception among Women in Tabriz/Iran
}

\author{
Sahar Azari', Mahnaz Shahnazi², Azizeh Farshbafkhalili³, Ommolbanin Abbasnezhad ${ }^{4}$
}

\begin{abstract}
Objectives: Approximately $48 \%$ of all pregnancies in the US are unintentional, unplanned, or mistimed and most unplanned pregnancies result from non-continuous, incorrect use or not using a contraceptive method. Choice of a method should be based on the effectiveness and protection provide against unwanted pregnancy. Aim of this study was determining reasons for choosing the traditional method (withdrawal) as contraception.

Materials and Methods: This is a cross-sectional descriptive study. The participants in this study consisted of 387 married women who used withdrawal method. Samples were selected randomly. A questionnaire was used for data collection. Descriptive statistics, Chi square, independent-samples t-test, Pearson test and one-way ANOVA were used for data analysis through SPSS 18.

Results: Findings indicated that 121 (31.3\%) women chose this method because they were sure that, it has same influences as other contraceptive methods, 114 (29.5\%) ones chose it due to fearing of infertility by other contraceptive methods and 64 (16.5\%) women said that their husbands are reluctant to use other methods.

Conclusion: The results showed that the wrong believes or lack of information cause women to choose this unsafe method. So providing women with necessary information in this field by health care providers can be most effective way for replacing effective methods and preventing unwanted pregnancy.

Keywords: Contraceptive methods, Tabriz, Withdrawal, Women
\end{abstract}

\section{Introduction}

One of the major issues of the last century is high rate of population growth especially in developing countries that has led to imbalance between the population growth and economic development, health care, housing, etc. (1). Population growth rate in Iran between 1956 and 2006 has slowed down from $2.12 \%$ to $1.16 \%$ which indicates Iran's relatively improved condition, but to achieve the planned fertility and high quality family planning services, there is still a long way to go (2).

Family planning (using contraceptive methods) means prevention of high-risk pregnancies, unplanned pregnancies and ultimately illegal abortions. On the other hand, the family planning program enables couples and individuals to decide freely and responsibly about the number and age difference of their children and enjoy the information and equipment to reach this goal. Also, a confident and informed choice about pregnancy and access to a complete collection of effective, reliable, cheap, acceptable and the best available contraception methods that are not illegal are the essential rights of men and women $(1,3)$.

One of the most dangerous choices of women about unintended pregnancy is illegal and unhealthy abortions by unauthorized persons that lead to infections, bleeding and death of mothers (4). The results of some studies indicated that most of the premature or low birth weight infants are the result of an unwanted pregnancy (5)

Modern age of contraception began since 1960 which at that time U.S. Food and Drug Administration (FDA) agreed the use of contraception pills (1). Nowadays, there are improved and reliable medical methods (hormonal contraception, IUD) in all health care centers for women. Despite the fact that there are many different medical methods, the conventional old method is still the most prevalent methods in many countries like Iran and Italy (6). Although the modern methods of contraception are available without charge in all health care centers of cities and rural areas of Iran, the application of traditional withdrawal method is still $21.7 \%$ in cities and $4.6 \%$ in rural areas. For example, about $29.3 \%$ of women in Tabriz use the conventional contraception method (2).

Conventional method (withdrawal coitus) is one of the oldest ways of voluntary birth control and along with induced and intentional abortion and marriage in older age is the major portion of decline in fertility in Europe before industrialization and it seems that they are still widely used. Some couples use this method successfully and some others find it difficult. The main weakness of this method is that seminal fluid before ejaculation may

Received 4 February 2014, Revised 10 May 2014, Accepted 1 July 2014, Available online 20 July 2014

${ }^{1} \mathrm{MSc}$, Department of Medical Science, Tabriz Branch, Islamic Azad University, Tabriz, Iran. ${ }^{2} \mathrm{MSc}$, Department of Midwifery, Faculty of Nursing and Midwifery, Tabriz University of Medical Sciences, Tabriz, Iran. ${ }^{3} \mathrm{PhD}$ student of by research, Department of Midwifery, Faculty of Nursing and Midwifery, Tabriz University of Medical Sciences, Tabriz, Iran. 4 BSc in midwifery, Urmia University of Medical Sciences, Urmia, Iran.

*Corresponding Author: Azizeh Farshbafkhalili, PhD Student of by research, Department of Midwifery, Faculty of Nursing and Midwifery, Tabriz University of Medical Sciences, Tabriz, Iran. Tel: +989143014293, Email: azizeh_farshbafkhalili@yahoo.com 
contain sperms. Another known disadvantage is the time of withdrawal since a short delay in withdrawal may shed a certain amount of sperm in vagina. Withdrawal is $81 \%$ effective at preventing pregnancy. With perfect use, it can be as high as $96 \%$ effective (3). Failure rate in withdrawal method is $4 \%(1)$.

The main disadvantage of this method is the high probability of pregnancy and risk of sexual diseases transparency. Shortcomings are depression and anger (7), lack of complete sexual satisfaction, no satisfaction in premature ejaculation and high refractive index $(8,9)$. Using safe methods not only prevent from increasing the population, it also improves the women health and protects them against illegal abortion, infection and death (10).

Given the widespread use of the withdrawal method and its role in population growth and unplanned pregnancies and its complications, developing the guidelines for safer alternatives seems to be necessary. Clearly identifying the factors influencing the select of withdrawal method is one way of achieving this goal. Considering the high prevalence of withdrawal method in Tabriz (2), limited studies and the impact of different cultures and traditions, this study conducted with the aim of determining the reasons that lead to the selection of withdrawal method in women referring to health centers of Tabriz in 2011-2012. It is expected the results of this study contribute to a safer alternative with lower refractive index.

\section{Material and Methods}

This cross-sectional descriptive study was conducted in 2011-2012. The target population consisted of 15-45 years old and married women who referred to the health care centers. Considering the prevalence of withdrawal method (37.8\%) with 0.95 confidence and 0.05 error and considering $10 \%$ likely drops in the number of samples, the initial number of samples was 352 and the final samples opted was 387. At first, the list of all health care centers of Tabriz was provided (from all 65 centers). Then, the samples were collected in 2 rounds through the multi-stage cluster sampling. Among 27 centers and 38 sub centers, 22 centers (including 9 centers and 13 sub-centers) randomly were selected. In the next step, regarding the sample size, 16-18 cases among all mothers clinical records were selected randomly $(16 \times 22=352,18 \times 22=396)$ and after phone call with women who had this study's eligibility criteria and explaining about the study, they were invited to fill the questionnaires (containing socio-demographic information and the causes of using withdrawal method). Sampling was done with random selecting manner in both stages through the http://www.randomizer.org website. The study's eligibility criteria were: being interested in participation in the research, being married and 1545 years old, without history of infertility and use of two contraceptive methods contemporary, not being menopause and pregnancy during the study. In this study, data were collected by researcher-regulated questionnaire that codified with reading the articles and different books. The questionnaire consisted of two parts. The first section contained 9 questions about women's demographic characteristics and obstetric history and second section contained 9 other questions about withdrawal method and reasons for using it. Content validity was used for scientific validity of questionnaire. Thus after several scientific studies with supervisor, data collecting tool was provided and the content of that evaluated by 10 academic members of Tabriz University of Medical Sciences. After collecting all opinions, we reformed and made some changes in it and made it ready for the research. For determining internal consistency of questionnaire, Cronbach alpha ( $\alpha=82 \%)$ was used through implementing it on 50 women.

Written consent was obtained from participants and for confidentiality, names not mentioned in the questionnaire forms. Self-report data were recorded in a two-part questionnaire. Those who were not willing to fill out the questionnaire, did not wish to continue participating in the study and had changed their contraceptive method were excluded from the study. Statistical analyses were done using the SPSS software version 18 descriptive statistics (absolute and relative frequency, mean, standard deviation, minimum and maximum), Chi square, independent-samples t-test, Pearson test and one-way ANOVA. P less than 0.05 were considered significant.

\section{Results}

Research was performed on 387 married women who had been using the withdrawal method. The mean (SD) age of participants was $30.09 \pm 5.31$, and most of the samples were in the age group of $25-29$ years (36.4\%). The mean (SD) number of pregnancy was $1.82 \pm 1.02$ and number of children was $1.51 \pm 0.64$ and average duration of using the present method was $73.75 \pm 53.54$ month. Other details can be seen in Table 1.

There was significant relationship between duration of using the withdrawal method with age, job, Marriage duration, length of marriage, number of pregnancies and gender of children $(\mathrm{P}<0.05$; Table 1$)$. The most important source of information about withdrawal method was the family (35.4\%) (Table 2). The study revealed that the most common reasons of using the withdrawal methods was having confidence in the success of this method (31.3\%), fear of infertility with medical practices $(29.5 \%)$, husband unwillingness to use other methods (16.6\%) (Table 3).

\section{Discussion \\ Based on the results of this study, majority of women were in age group with the highest chance of pregnancy and this shows the importance of giving education and awareness about unwanted pregnancy and its side effects. Results of this study showed that ensuring similar efficacy in compare with medical methods, fear of infertility with medical practices and husband refusing to use the other contraceptive options were the main reasons for selecting withdrawal methods. It is somewhat similar to other studies. In a study entitled the reasons of women using withdrawal methods instead of medical}


Table 1. Correlation between socio-demographic and obstetrics characteristics with duration of using the withdrawal method

\begin{tabular}{|c|c|c|c|}
\hline Variable & & N (\%) & $\mathbf{p}$ \\
\hline Age (Mean $\pm S D)$ & $30.09 \pm 5.31$ & & 0.00 \\
\hline Marriage duration (Mean $\pm S D$ ) & $12.04 \pm 5.12$ & & 0.00 \\
\hline \multirow{3}{*}{ Occupation } & Housewife & $368(95.1)$ & \multirow{3}{*}{0.00} \\
\hline & Occupied at home & $3(0.8)$ & \\
\hline & Occupied outside home & $16(4.1)$ & \\
\hline \multirow{2}{*}{ Husband's job } & Employer & $116(30$ & \multirow{2}{*}{0.03} \\
\hline & Private Job & $271(70)$ & \\
\hline \multirow{3}{*}{ Education } & Illiterate & $2(0.5)$ & \multirow{3}{*}{0.00} \\
\hline & Elementary school & $306(79.1)$ & \\
\hline & High school & $79(200.4)$ & \\
\hline \multirow{3}{*}{ Husband's education } & Illiterate & $1(0.3)$ & \multirow{3}{*}{0.72} \\
\hline & Elementary school & 293 (7/75\%) & \\
\hline & High school & $93(24)$ & \\
\hline \multirow{3}{*}{ Gender of children } & Boy & $138(35.7)$ & \multirow{3}{*}{0.00} \\
\hline & Girl & $154(39.8)$ & \\
\hline & Boy and girl & $95(24.5)$ & \\
\hline
\end{tabular}

methods, Rahnama et al. showed that factors such as free procedure, no need for a physician's order and low side effects, no health concerns, lack of trust to other methods and comfortable using of withdrawal method were the reasons for choosing this method (11). Whittaker et al. on their study entitled experiences of withdrawal method, expressed convenience of withdrawal method and lack of satisfaction with the other methods as the most important reasons in the choice of withdrawal method (12). These findings differ somewhat from our results that may be due to difference in beliefs and customs of the region. Most common sources of information in the present study were relatives that were different from the results of Amir ali akbari et al. study. In their study, the common sources of information were health workers $(26.6 \%)$ and media (16.9\%), the difference could be due to cultural differences and family relationships. Another difference between the

Table 2. Sources of information about the withdrawal method as a contraceptive way in women.

\begin{tabular}{lc}
\hline Information Sources & $\mathbf{N}(\%)$ \\
\hline Family & $137(35.4)$ \\
Other sources & $63(16.3)$ \\
Education during schooling & $47(12.1)$ \\
Husband & $46(11.9)$ \\
Books and magazine & $42(10.9)$ \\
Friends & $20(5.2)$ \\
Doctor & $13(3.4)$ \\
Education before marriage & $12(3.1)$ \\
Training provided at health care centers & $4(1)$ \\
Midwifes & $2(0.5)$ \\
Radio and TV & $1(0.3)$ \\
Total & $387(100)$ \\
\hline
\end{tabular}

results of two studies could be the lack of confidence in health staff or flaws in communication and information transfer to the client and because of that Health workers require more effort (13). The role of media in our study like Shirvani's study was not considerable (14).

In this study, the majority of women were housewives (95.1\%) and their spouses were self-employed (70 percent). Amir ali akbari study indicated the majority of women were housewives $(78.1 \%)$ and their husbands were self-employed (61.7\%) (13). The results of this study about age rang were coordinated with other studies Amir ali akbari et al. and Ahmad Shirvany's study $(13,14)$. There was a significant relationship between age and contraceptive method, which is in line with our study (13). The results of Mehryar et al., Yosefzade and Ergocmen et al. studies showed that there was a significant relationship between age and contraceptive method $(7,15,16)$.

Table 3. Causes of choosing withdrawal method as a contraceptive way in women.

\begin{tabular}{lc}
\hline Causes of choosing withdrawal method & N (\%) \\
\hline Having confidence in the success of this method & $121(31.3)$ \\
Fear of infertility with medical methods & $114(29.5)$ \\
Husband unwillingness for using other method & $64(16.6)$ \\
Not being comfortable with other methods & $31(8)$ \\
Fear of side effects of other medical methods & $28(7.2)$ \\
Being Indifferent towards pregnancy & $10(2.6)$ \\
Medicine prohibition & $6(1.6)$ \\
Experiencing complications with other methods & $4(1)$ \\
Difficulty in traveling to the health centers and & $4(1)$ \\
stations & $1(0.3)$ \\
Lack of knowledge about other medical methods & $2(0.5)$ \\
Shame of consulting with others about contraceptive & $1(0.3)$ \\
methods & $1(0.3)$ \\
Family Opposition & $387(100)$ \\
Conflict with religious beliefs & \\
Total &
\end{tabular}


They were consistent with the results of our study. In our study, there was a significant correlation between duration of the withdrawal method and age, job, ength of marriage, number of pregnancies and number of live offspring, $(\mathrm{P}<0.05)$. It was consistent with Amir aliakbari et al study (13).

\section{Conclusion}

These results indicate the lack of proper education and inadequate training and consulting in selection of the contraceptive methods. Our study show that although there is development in medical contraceptive methods, there are still some people who prefer to use traditional method (withdrawal) due to some wrong beliefs and information. Because of the popularity of using withdrawal method, it is needed to give correct information about fail rate of the method, high possibility of unwanted pregnancy and also recognize incorrect beliefs and try to correct of them. It is essential to introduce the secure medical methods that are proper for different people mentioning their advantages and effectiveness. Also, this survey shows the importance of men's decision in selecting contraceptive method and giving education to them can make a big evolution in using certain contraceptive methods.

So, besides training of women and giving appropriate education in different levels prior-to marriage education should never be ignored. Perhaps it is time that men participate in consulting meetings for contraceptive method in developing countries.

Limitations: In this study, we investigated about withdrawal method just in Tabriz It is recommended to conduct studies about other cities.

\section{Ethical issues}

The local ethics committee approved the study.

\section{Conflict of interests}

Authors declare that there is no any conflict of interests.

\section{Acknowledgments}

The authors gratefully acknowledge the Tabriz Medical University, which approved and supported this project. We thank the all participants for their cooperation.

\section{References}

1. Fritz mark A. Clinical gynecologic endocrinology and fertility.8th ed.philadelphia: lippincott williams\& wilkins;2011.p.373-562

2. URL: http://www.sci.org.ir/portal/faces/public/ census85/census85.natayej/census85.gozideh

3. Hatami H, Ardebili H, Nozadi M, Parizade M. Text book of republic health. 2nd ed. Tehran: Arjmand pub.: 2009. p.1598.

4. Speizer IS, Santelli JS, Afable-Munsuz A, Kendall C. Measuring factors underlying intended ness of women's first and later pregnancies. Perspect Sex Report Health 2004; 36(5):198-205.

5. Afshar M, Delavardin N, Kiyanfar S. Comparing growth factors in neonate in unwanted pregnancies. Journal of health University 2003;55(2):620.

6. Detels R, Beaglehole R, Lansang M, Gullifard M. Textbook of public health. 5th ed. Oxford: Oxford University press;2011. p.1598.

7. Yosefzade S. Servey on the efficacy and complications of different contraceptives in women. Asrar J 2001;7(2):43-53.

8. Borojerdi N. Family health and midwifery. Tehran: Jamenegar; 2005. p.33.

9. Fallah K. Family planning and consultant. Tehran: Shahr ab pub;2003. p.137-138.

10. Milsom 1. Contraception And Family Planning.1st ed. United Kingdom: Elsevier;2006.

11. Rahnama P, Hidarnia A, Amin Shokravi F, Kazemnejad A, Ghazanfari Z. Why Iranian married women use withdrawal instead of oral contraceptives? A qualitative study from Iran. BMC Public Health 2010;10:289.

12. Whittaker P, Merkh R, Enry-Moss D, Hock-Long L. Withdrawal attitudes and experiences: a qualitative perspective among young urban adults. Perspect Sex Reprod Health 2010;42(2):102-9.

13. Amir ali akbari S, Niyaki $M$, Ahmadi $M$, Alavi H. Cause of using a traditional method in Amol. Mazandaran Medical University Journal 2001;15(48):92-8.

14. Shirvani M. Related factors about using contraceptive methods. Hayat 2006;13(3):37-47.

15. Mehryar A, Aghajanian A, Delavar B, Eini-Zinab H, Kazemipour S. Continuing use of a traditional method (withdrawal) in a high contraceptive prevalence country, Iran: Correlates and consequences. Paper accepted for presentation at the XXV General Population Conference of the International Union for the Scientific Study of Population.

16. Ergocmen B, Koc I, Senlet P, Yigit E, Roman E. A closer look at traditional contraceptive use in Turkey. Eur J Contracept Reprod Health Care 2004;9(4): 221-44.

Copyright $(2014$ The Author(s); This is an open-access article distributed under the terms of the Creative Commons Attribution License (http://creativecommons.org/licenses/by/4.0), which permits unrestricted use, distribution, and reproduction in any medium, provided the original work is properly cited. 